\title{
LEBNER, Ashley. Redescribing relations: Strathernian conversations on ethnography, knowledge and politics. New York: Berghahn Books, 2017. 252 p.
}

\author{
Magda dos Santos Ribeiro* \\ * The University of Manchester - Manchester, Reino Unido \\ Rutherford Fellow \\ magda.dossantosribeiro@manchester.ac.uk \\ https://orcid.org/0000-0003-3322-1363
}


Parte da frustração que acompanha a leitura de Marilyn Strathern pode estar relacionada ao seu estilo meta-antropológico e à sua agenda comparativa, tal como conjecturado no volume da Theory, Culture and Society dedicado à autora (Street; Copeman, 2014). Não obstante, suas estratégias e técnicas originais, cujo efeito produz diferenciação, analogia, bifurcação e eco, fazem eclodir a maneira como tornamos nossas categorias de análise conhecidas e retidas por nós mesmos. Mas reconhecer que Strathern é uma autora fundamental de sua geração não contempla inteiramente o legado que tem oferecido à antropologia, e embora muito tenha sido escrito sobre a complexidade de sua obra e o alcance de sua influência (Gell, 1999), a intensidade de suas ideias continua reverberando no coração da disciplina.

Marilyn Strathern pode começar um ensaio percorrendo uma vinheta etnográfica, suscitar questões e arriscar-se a respondê-las por meio de outra vinheta, cultivando, assim, um aspecto enigmático de seu objeto ao invés de oferecer ao leitor sua chave. Na antropologia de Strathern a forma compõe o argumento, muito mais no espírito atraente que convida ao envolvimento do que na obrigação de respeitar os termos de um contrato teórico. É precisamente este movimento - o de transformar a forma argumentativa ao atravessar escritos outros - que Ashley Lebner chama de redescrição (p. 2). Uma redescrição, com efeito, implica lançar mão de outras relações. Para ler Strathern, sugere de saída, devemos prestar atenção às palavras e às formas, assim como na relação entre elas as quais compreendem, bem sabemos, importantes distinções (p. 2).

Redescribing relations: Strathernian conversations on ethnography, knowledge and politics, idealizado e organizado por Ashley Lebner, é resultado do empenho de pesquisadores engajados com o trabalho de Strathern, o qual, segundo argumentam, multiplicou nosso senso acerca do que a antropologia é capaz de fazer (p. 3). A versão única de antropologia desvelada por essa autora é construída precisamente em torno do princípio de que devemos manter constantemente - entre nós antropólogos, mas sobretudo entre nossos escritos - uma conversação crítica. A redescrição - uma noção central à obra e delineada por Lebner em trabalhos anteriores (Lebner; Deiringer, 2008-2009) - é longamente explorada com o objetivo de elucidar o projeto intelectual mais amplo de Strathern, colocando em relevo a quantidade impressionante dos temas por ela tratados e que trespassam os domínios do parentesco, gênero, ciência, lei, economia e burocracia (p. 3). 
Em particular no Brasil, Strathern tem sido lida, grosso modo, por duas vertentes: a etnologia (enquanto uma melanesista) e os estudos de gênero (em diálogo com a abordagem feminista). Contudo, como sugere Lebner, o projeto de Strathern deve menos ser compreendido pela via de seus eixos temáticos e mais por seu viés metodológico. Tem como característica marcante a torção de ideias e temas, conjugando-os de maneira absolutamente original, onde acopla uma espécie de rejeição às grandes teorias com um objetivo bastante singular - um destino que é, naturalmente, uma tarefa permanente e incansável, já que nenhuma descrição é perfeita ou definitiva (p. 3). Essa é a razão mais elementar pela qual a redescrição, em uma palavra, é capaz de capturar sua abordagem antropológica (p. 4).

Lebner, ao erigir a redescrição como síntese do gesto stratherniano, incorpora, mais do que revisita, os argumentos da autora. Os termos empregados e o modo como entrelaça artifícios descritivos são exemplos de seus esforços em reformular uma formulação, com atenção persistente à linguagem analítica. Nessa direção, a redescrição stratherniana deve ser entendida principalmente como uma série de relações, definida de maneira mais abrangente como o estabelecimento de conexões e distinções conceituais e interpessoais que sustentam a vida social (p. 3). Lebner enfatiza que para Strathern toda palavra importa: mesmo que as ideias possam ser relacionais, facultar à antropologia a tarefa de criar e cuidar de conceitos é uma proposição muito diferente de "nos relacionarmos com as relações [using relations] para revelar as relações [to uncover relations]" (p. 3).

A noção de relação, com efeito, é notadamente reconhecida como o epicentro da obra de Strathern, matizada em muitos de seus textos e sob abordagens as mais diversas. Para essa autora há algo único produzido pelas relações. Esse algo pode ser um conceito, um tipo de conhecimento, uma prática, uma formulação, uma abstração, uma matéria, ou a combinação desses atributos. A relação instancia as conexões ao mesmo tempo em que produz instâncias para si mesma (Strathern, 2003). Poderíamos chamar a relação de um construto autossimilar ou auto-organizável, uma figura cujo poder organizador não é afetado pela escala (Strathern, 2014). Muito embora Lebner não se dedique propriamente em trazer à tona o modo como a noção de relação orienta os escritos de Strathern, como já fizeram outros autores (Holbraad; Pedersen, 2010; Jiménez, 2004), seu esforço está em demonstrar como a redescrição opera, justamente, por meio de uma série de relações. 
Além de dedicar-se longamente à exposição dos principais operadores analíticos strathernianos - dentre eles a própria noção de relação - ela enfatiza como as estratégias de deslocamento, analogia, relações e política estão intimamente implicadas umas nas outras (p. 4). Lebner endereça outras discussões e polêmicas, tal como a defesa do argumento de que o trabalho de Strathern não deve ser assimilado à virada ontológica (p. 23), como vem sendo feito insistentemente (por exemplo, em Holbraad; Pedersen, 2010, 2017).

A obra, assim, busca antes de tudo oferecer entendimentos aprofundados acerca dos escritos e das ideias de Strathern através de uma densa introdução, "Strathern's redescription of anthropology" (p. 1-37), escrita pela autora do volume, e por meio da seleção e reunião de capítulos escritos por diversos autores, todos inspirados e deliberadamente comprometidos com noções e ideias strathernianas.

Alguns dos textos que compõe a obra são referências já familiares ao leitor brasileiro, tal como a entrevista realizada por Eduardo Viveiros de Castro e Carlos Fausto (1999) (cap. 1) e o texto "Slow motions: comments on a few texts by Marilyn Strathern", publicado anteriormente no The Cambridge Journal of Anthropology (Viveiros de Castro; Goldman; Lebner, 2008-2009) e apresentado nesse volume em sua versão extended remix, como a intitularam Viveiros de Castro e Goldman (cap. 7). Os demais textos oferecem capítulos teóricos e/ou etnográficos sob influência das ideias de Marilyn Strathern e tendem a privilegiar o debate metodológico ao mesmo tempo em que auxiliam na compreensão da abordagem stratherniana ao estendê-la para outras arenas etnográficas. É o caso das contribuições de Carol J. Greenhouse (cap. 2), Alberto Corsín Jiménez (cap. 3), Stuart Kirsch (cap. 4); Yael Navaro (cap. 5) e Casper Brrun Jensen e Brit Ross Winthereik (cap. 6).

Não obstante, o tom da obra oblitera qualquer julgo crítico aos métodos strathernianos ou aos seus efeitos analítico-políticos, já que se estatui como uma obra-homenagem. Lebner (p. 25) não deixa de reiterar, em diversas passagens, o quanto a inspiração stratherniana foi transformadora em sua trajetória intelectual e o modo como "seu pensamento pode estimular a antropologia e a reflexão política da maneira mais inesperada." (p. 25). Consciente das frequentes críticas dirigidas à autora, mas contudo sem retomá-las, Lebner (p. 20) escreve em sua defesa, sobretudo no que se refere à licença binária - tema presente também na conclusão, escrita por Sarah Green (p. 205) - e o lugar da política em sua estratégia de redescrição. 
O volume é, portanto, dirigido àqueles que se deixam - ou querem deixar-se - afetar pelas (re)descrições de Marilyn Strathern, mas, igualmente, que desejam conhecer a repercussão de sua obra em diferentes pesquisas etnográficas e análises antropológicas.

\section{Referências}

GELL, A. Strathernograms, or the semiotics of mixed metaphors. In: GELL, A.; HIRSCH, E. (ed.). The art of anthropology: essays and diagrams. Oxford: Berg, 1999. p. 29-75.

HOLBRAAD, M.; PEDERSEN, M. A. Planet M: the intense abstraction of Marilyn Strathern. Anthropological Theory, v. 9, n. 4, p. 371-394, 2010.

HOLBRAAD, M.; PEDERSEN, M. A. The ontological turn: an anthropological exposition. Cambridge: Cambridge University Press, 2017.

JIMÉNEZ, A. C. The form of the relation, or anthropology's enchantment with the algebraic imagination. 2004. Disponível em: http://digital.csic.es/bitstream/10261/98307/1/ the\%20form\%20of\%20the\%20relation.pdf. Acesso em: 28 jan. 2018.

LEBNER, A.; DEIRINGER, S. Editors' note. The Cambridge Journal of Anthropology, v. 28, n. 3, p. 1-5, 2008-2009.

STRATHERN, M. Endnote: redescribing society. In: STRATHERN, M. Commons and borderlands: working papers on interdisciplinarity, accountability and the flow of knowledge. London: Sean Kingston, 2003. p. 87-102.

STRATHERN, M. Reading relations backwards. Journal of Royal Anthropological Institute, v. 20, n. 1, p. 3-19, 2014.

STREET, A.; COPEMAN, J. Social theory after Strathern: an introduction. Theory, Culture and Society, v. 31, n. 2-3, p. 7-37, March/May 2014.

VIVEIROS DE CASTRO, E.; FAUSTO, C. No limite de uma certa linguagem: entrevista com Marilyn Strathern. Mana, Rio de Janeiro, v. 5, n. 2, p. 157-175, 1999.

VIVEIROS DE CASTRO, E.; GOLDMAN, M.; LEBNER, A. Slow motions: comments on a few texts by Marilyn Strathern. The Cambridge Journal of Anthropology, v. 28, n. 3, p. 23-42, 2008-2009. 